\title{
Interactions of double slanted cracks under mode I loading
}

\author{
Al Emran Ismail, Muhd Hafeez Zainulabidin, Fazimah Mat Noor, Hanani Abd Wahab, Maznan Ismon, Zaleha Mohamad, \\ Mohd Amran Madlan \\ Crashworthiness and Collision Research Group (COLORED), Mechanical Failure Prevention and Reliability (MPROVE), Faculty of \\ Mechanical and Manufacturing Engineering, Universiti Tun Hussein Onn Malaysia, Batu Pahat, 86400 Johor, Malaysia
}

\begin{abstract}
This paper presents numerical analysis of double slanted central cracks in square plates under mode I tension stress. ANSYS finite element program is used to model and solve the problem of slanted cracks where the stress intensity factor is determined according to J-integral approach. Three relative crack length, a/ $\mathrm{W}=0.1,0.2$ and 0.3 is used while relative spacing between the cracks, $\mathrm{s} / 2 \mathrm{a}$ are ranged between 0.1 to 0.6 . In order to study the roles of slanted cracks on the stress intensity factor, several slanted angles are used such as $0^{\circ}, 15^{\circ}, 30^{\circ}, 45^{\circ}, 60^{\circ}$ and $75^{\circ}$. According to the numerical analysis, all parameters above played an important role in determining the stress intensity factors. As expected, longer crack produced higher stress intensity factor. For the cracks with $\mathrm{a} / \mathrm{W} \leq 0.2$, insignificant crack interaction is observed however when crack reached $\mathrm{a} / \mathrm{W}=0.3$, the interaction is gradually increased. Increasing the slanted angles slightly increased the interaction factor however the effect of relative crack spacing became insignificant.
\end{abstract}

\section{Introduction}

The formations of cracks are strongly depend on the type of materials, loading, environmental aggression and design condition of mechanical components. In general, crack grown perpendicularly to the axis of loading however under circumstances, crack also propagates obliquely especially as a result of hydrogen induced cold crack after the metal welding. In this case, most of cracks appeared not in a single crack but in the form of multiple cracks.

Tremendous amount of works can be found in analysing the normal cracks in open literature [1-3]. For examples Matsumto et al. [1] evaluated the stress intensity factor of normal crack along two different materials using an interaction energy release rate and boundary element method. In order to indicate the reliability of their method, some numerical models are used and compared. The present method capable to produce more accurate results with a coarse mesh than the method based on the displacement extrapolation which is based on the boundary element method.

Hammond and Fawaz [2] reviewed stress intensity factors of various size single edge-cracked tension specimens. Finite element method is used to calculate the stress intensity factors for wide ranges of crack and sample geometries. Comparison is also performed between the existing and their results generally satisfactory correlation and large differences about $12.7 \%$ is observed for short cracks in small plate aspect ratio.

Ismail et al. [3] investigated stress intensity factors of double edge cracks in large groove plate under mode I tension. They used finite element method to determine the stress intensity factor via domain integral method. It is found numerically that the SIFs are strongly affected by the relative crack depth and the groove geometries. It is also found that the large groove is capable of reducing the SIFs in comparison with the circular notched due to lower stress concentration factors.

Several works discussed on the multiple normal cracks can also be found in [4-8]. For examples Yan and Miao [4] studied the interaction of multiple cracks in a rectangular plate using boundary element method. They reported that the boundary element method is simple yet accurate for determining the stress intensity factors of multiple crack problems. While, Yang and Soh [5] developed finite element method using complex potential and the conformal mapping technique to study the multiple crack problems. It is found that the method developed useful for modelling the crack interactions between many cracks and defects.

Shu et al. [6] studied the problems of three cracks on both edges of finite width sheet under mode I loading. They modelled the multiple cracks using finite element method and due to symmetrical effect only half of model is developed. They found that when there are several cracks existed, the flexibility of the plate increased and the stress intensity factors at the crack tips decreased.

Ismail [7] studied the stress intensity factors of three parallel edge cracks under bending moments. Cracks are modelled using finite element method and different relative crack length and spacing between cracks are used. It is found that due to the presence of multiple crack edge cracks, the stress distribution is relaxed and therefore, the 
stress intensity factors for all cracks decreased and when the distance between the cracks is increased, interaction is seemed to be diminished and it is can be neglected especially for swallow crack. The behaviour of offset crack under mixed mode loading can also be found in [8].

In term of slanted cracks, several works are found such as [9-11]. Kuang and Chen [9] used a displacement extrapolation method to investigate the mixed mode crack problems under mode I loading. There are two important parameters are used such as crack length and size of element at the crack tip. However, the crack is only slanted at limited angle then it is hard to understand the role of angles on the stress intensity factors.

Albinmousa et al. [10] provided solution of stress intensity factors for mixed mode I-II single edge notched tension specimen. Wide range of crack geometries and inclined angles are used and stress intensity factors are determined based on such parameters. Then, curve fitting is performed to simplify the stress intensity factors for prediction purposes. They found that their model can be used to predict the stress intensity factors very well. Another study on the slanted crack can be found in [1113]. However, this work focused on the three dimensional cracks.

However, there are lack number of publications available on the multiple slanted cracks. Therefore, this paper presents the numerical analysis on the double slanted cracks embedded in a plain strain plate under mode I tension pressure. Double slanted cracks are positioned in the central of $100 \times 100 \mathrm{~mm}$ plate where the relative crack length, $\mathrm{a} / \mathrm{W}=0.1,0.2$ and 0.3 . The cracks are also oriented using different angles such as $0^{\circ}, 15^{\circ}$, $30^{\circ}, 45^{\circ}, 60^{\circ}$ and $75^{\circ}$. The spacing distance between two slanted cracks are varied in the range of 0.1 to 0.7 . The stress intensity factors calculated from single and multiple cracks are analysed with the relations of parameters mentioned previously.

\section{Finite element modelling}

ANSYS finite element program is used to model and calculate the stress intensity factors (SIF) at the crack tips. In this work, SIFs are based on the J-integral calculated around the several integral contour around the crack tip. Figure 1 shows the schematic diagram of the double slanted cracks in square plate under mode I pressure with the assumption that the plate is fulfilled the plain strain condition. The dimension of plate is height, $\mathrm{H}=100 \mathrm{~mm}$ while width, $\mathrm{W}=100 \mathrm{~mm}$. On the other hand, crack length, $2 \mathrm{a}$ is varied by normalizing with $\mathrm{W}$ to produce $\mathrm{a} / \mathrm{W}=0.1,0.2$ and 0.3 . The distance between slanted cracks, $2 \mathrm{a} / \mathrm{S}$ are also varied between 0.1 and 0.6 . The orientations of cracks are also varied in order to study the effect of such angles on the crack behaviour. The values of angles used are $0,15^{\circ}, 30^{\circ}, 45^{\circ}, 60^{\circ}$ and $75^{\circ}$. These angles are then normalized against the angle of $90^{\circ}$.

Two types of cracks are used such as normal and slanted cracks as in Figures 2 and 3, respectively. For normal cracks, quarter model is used to take an advantage of symmetry while full model approach is implemented to model the slanted cracks. SIFs obtained numerically are then normalized according to Equation (1).

$$
F=\frac{K}{\sigma \sqrt{\pi a}}
$$

where, $F$ is a normalized SIF or geometrical correction factor, $K$ is a stress intensity factor, $\sigma$ is tension stress and $a$ is a crack length. Before the model is further used, it is a crucial task to compare the current with the existing models. Figure 4 indicates the validation of normal cracks when compared with the results obtained from Murakami [12]. For this kind of cracks, the present model is well validated and therefore it can be used for further analysis. In order to analyse the crack interaction, another factor is considered as in Equation (2).

$$
\psi=\frac{K_{\text {two-crack }}}{K_{\text {single-crack }}}
$$

where $\mathrm{K}_{\text {two-cracks }}$ is stress intensity factor obtained from interacting cracks and $\mathrm{K}_{\text {single-crack }}$ is stress intensity factor of single crack. According to Figure 1, there are four crack tips. Based on the preliminary work, the stress intensity factors at tip $\mathrm{A}$ is equal with tip $\mathrm{D}$ and on the other hand the stress intensity factor at tip B is similar with tip C. Then, for the sake of simplification on the stress intensity factors at crack tips $\mathrm{A}$ and $\mathrm{C}$ are presented and analysed.

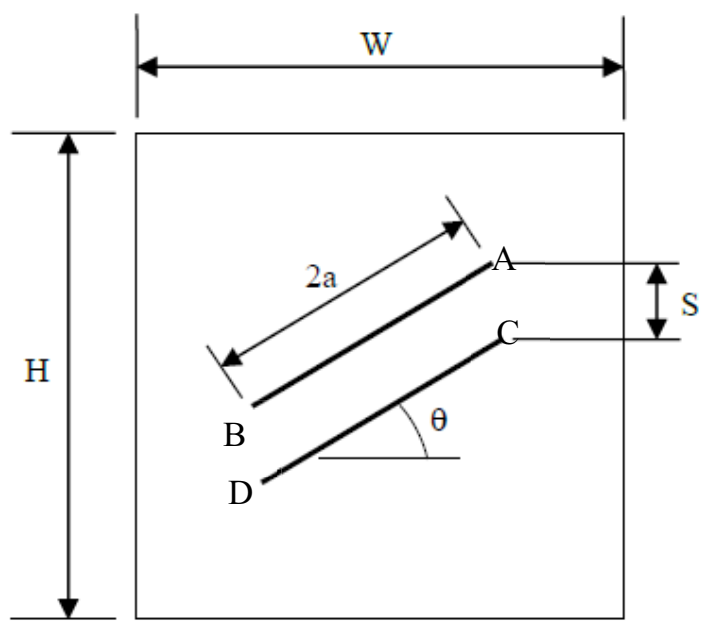

Figure 1. Schematic diagram of the slanted cracks.

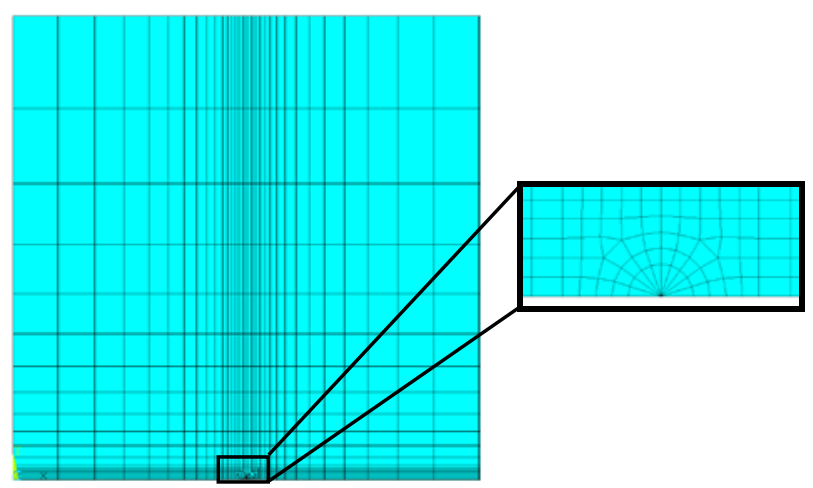

(a)

(b)

Figure 2. (a) Quarter finite element model and (b) Corresponding crack tip. 


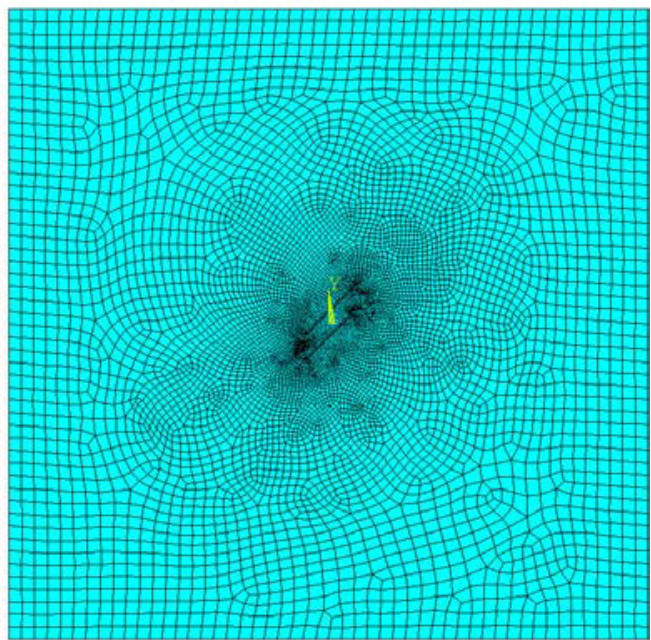

Figure 3. Double slanted crack.

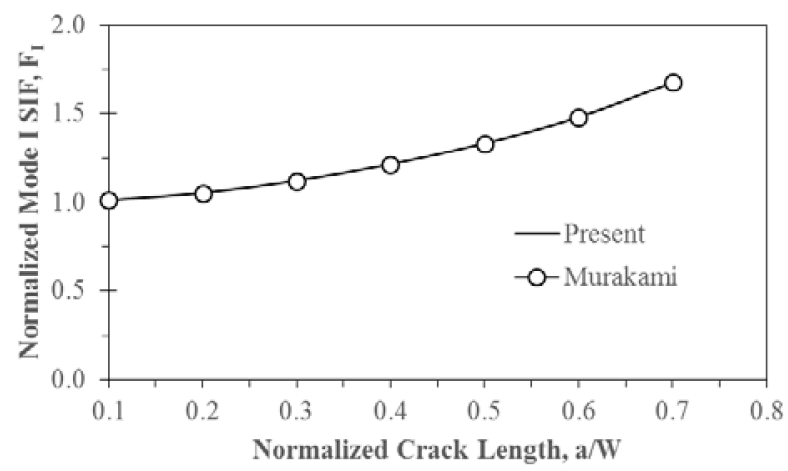

Figure 4. Validation of normal cracks.

\section{Results and discussion}

\subsection{The effect of crack spacing on the interaction factors}

Figure 5 shows the effect of the relative crack spacing on the interaction factors of different relative crack length when different slanted angles are used for a crack tip A. Figure 5(a) reveals the interaction factors of normal cracks which is the principal stress is perpendicular to the cracks. It is indicated that the interaction are almost uniform when crack length is increased since the stress around the crack is uniformly distributed. However when slanted angles are introduced, the effect of crack length is obvious as in Figure 5(b)-5(d) where for the crack length less than 0.2 , the factor of interaction are almost similar indicating the shielding effect. Whereas for crack length greater than 0.3 , the interaction factor increased gradually however it is still lower than the case of normal cracks. This is due to the fact that when the cracks are inclined, the capability of mode I loading to open the cracks are insignificant since the formation of mode I stress intensity factors are strongly related with such angles. Higher slanted angles higher shear stress are induced resulting lack of capability to open the crack faces. Figure 6 indicates the behaviour of interaction factors at the crack tip B. The role of such interactions are considerably similar however it is lower than the interaction for the case of crack tip A.

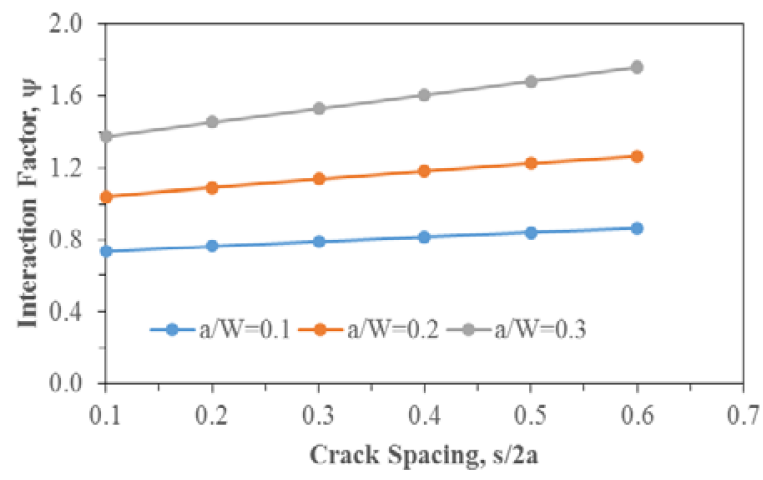

(a)

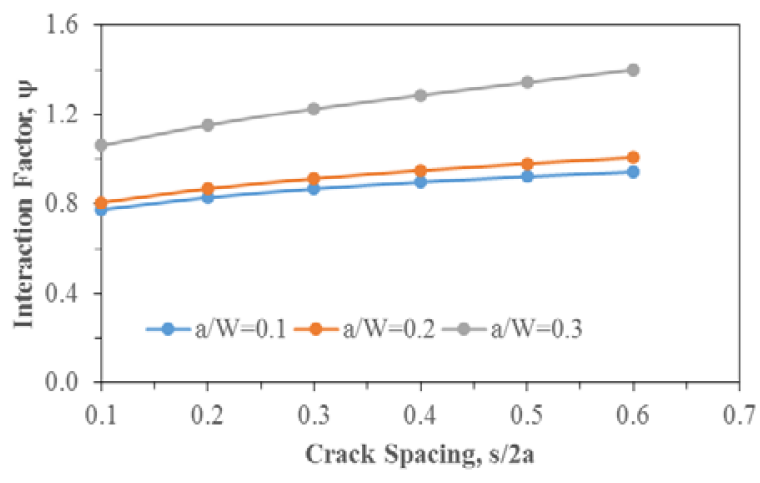

(b)

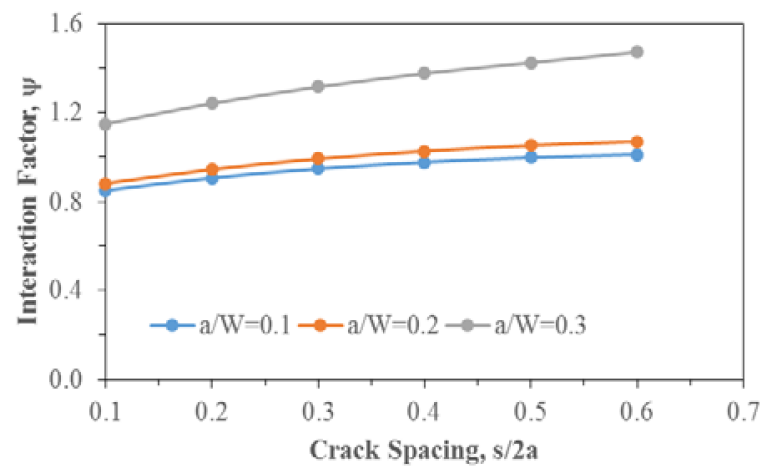

(c)

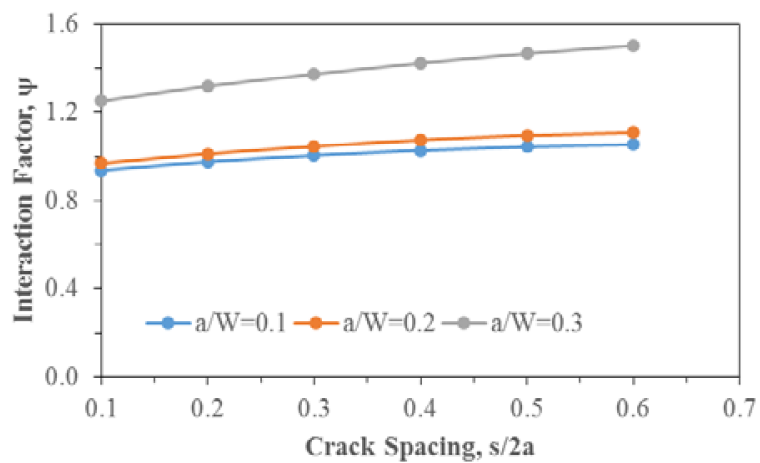

(d)

Figure 5. Effect of crack spacing on the interaction factor of (a) $0^{\circ}$, (b) $15^{\circ}$, (c) $45^{\circ}$ and (d) $60^{\circ}$ slanted angle cracks for crack tip A. 




(a)



(b)



(c)

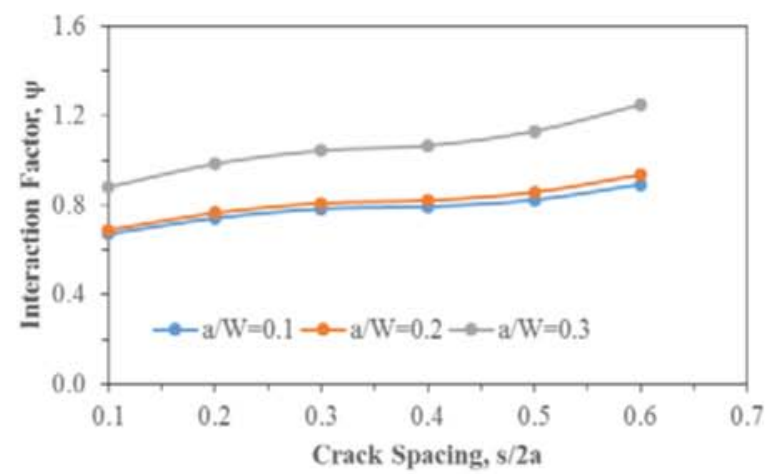

(d)

Figure 6. Effect of crack spacing on the interaction factor of (a) $0^{\circ}$, (b) $15^{\circ}$, (c) $45^{\circ}$ and (d) $60^{\circ}$ slanted angle cracks for crack tip c.

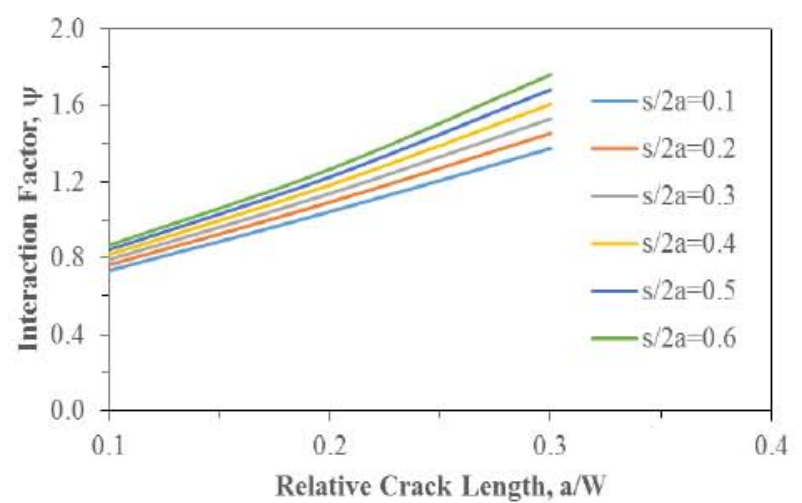

(a)

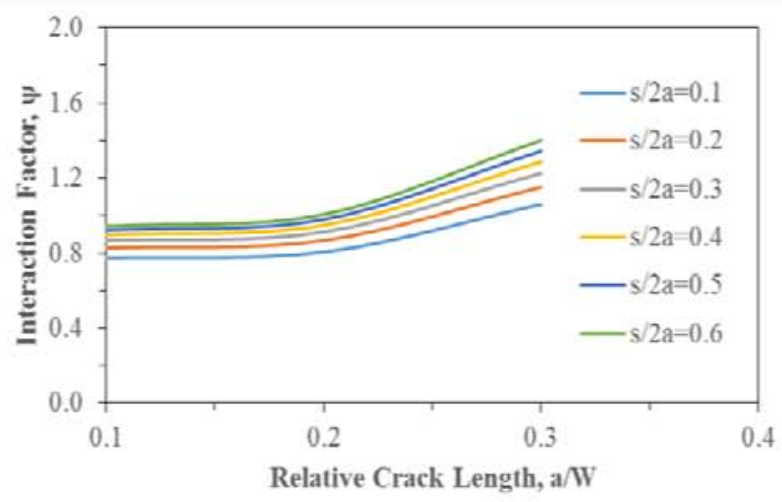

(b)

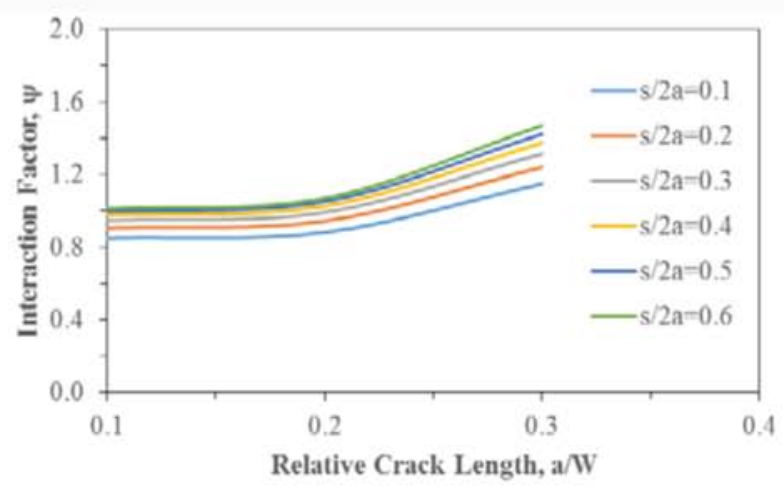

(c)

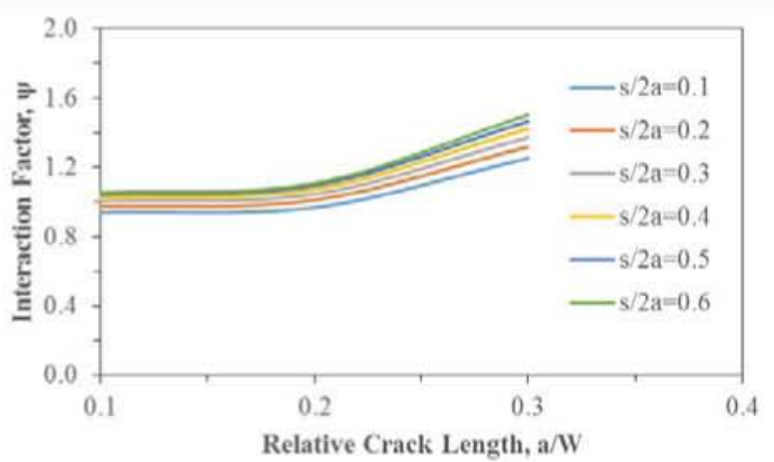

(d)

Figure 7. Effect of relative crack length on the interaction factor of (a) $0^{\circ}$, (b) $15^{\circ}$, (c) $45^{\circ}$ and (d) $60^{\circ}$ slanted angle cracks for crack tip A. 


\subsection{The effect of relative crack length on the factor of crack interactions}

Figures 7 shows the roles of relative crack length on the interaction factors when different slanted angles are used for crack tips $\mathrm{A}$ and $\mathrm{C}$, respectively. In general for all cases of crack tips, higher the distance between the cracks produced higher interaction factors. It is indicated that if the cracks are closed together shielding effect is produced while if the cracks are positioned away from each other, higher interaction factors are produced. It is indicated that the amplification effect is induced. In addition for crack length of 0.1 , the interaction factors are insignificantly varies however when relative crack length increased,

Figures 7(a) and 7(b) show the interaction factors of normal cracks. It is revealed that such interaction increased as relative crack length increased. Every increment of relative crack distance, increased the interaction factors indicating the existence of amplification effect. It is occurred when the cracks are away from each other and their stress intensity factors became similar to those of single cracks. It is also indicated that when crack length increased, the interaction factors are also increased. On the other hand, the interaction factors diverged slightly as relative length is increased. This is due to the fact that when longer crack length is used, the flexibility of the ligament between the cracks is lowered and therefore giving an advantage for the cracks to widely open.

The effect of slanted angles on the interaction factors can be observed in Figure 7(b)-7(d). Additionally, the distribution of interaction factors are strongly related to the positions of crack tips. For the case of crack tip A if the slanted angle is increased, the interaction factor is also increased slightly. This is due to the increment of shear force when the cracks are tend to the right angle. Insignificant effect on the interaction factors are observed when different relative crack distances are used. It is believed that at the crack tip A, the flexibility around the tip is unchanged leading to the insignificant variations of interaction factors.

Whereas at the crack tip $C$, the behaviour of interaction factor is significantly different where increasing the slanted angles have dispersed the distribution of such factors. This is probably due to the fact that the crack tip $\mathrm{C}$ is located below a crack tip A. therefore varying the relative crack distances varied the flexibility of the ligaments between them and then affecting the stress intensity factors.

\section{Conclusion}

In general, the interaction factors of normal cracks under mode I loading can be easily predicted since the stress intensity factors are the function of relative crack length. However for the case of slanted cracks, the crack interactions strongly related with the relative distance among them. If the cracks are positioned close to each other shielding effect took place and if it is far away amplification effect is induced. On the other hand, position of crack tips are also played an important role since each tip produced considerably different characteristics.

\section{Acknowledgement}

Author acknowledges Universiti Tun Hussein Onn Malaysia for financially supporting this work.

\section{References}

1. T. Matsumto, M. Tanaka, R. Obara. Engineering Fracture Mechanics 65, 683-702 (2000)

2. M.J Hammond, S.A Fawas. Engineering Fracture Mechanics 153, 25-34 (2016).

3. A.E Ismail, MA Azlan, AL Mohd Tobi, MH Ahmad. IOP Conf. Series: Materials Science and Engineering 152012049 (2016).

4. X. Yan, C. Miao. Applied Mathematical Modelling 36, 5727-5740 (2012).

5. C.H Yang, A.K Soh. Theoretical and Applied Fracture Mechanics 38, 81-101, (2002).

6. H.M Shu, J. Petit, Z.D Jiang, G. Bezine. Engineering Fracture Mechanics 45, 407-414 (1993).

7. A.E Ismail. IOP Conf. Series: Materials Science and Engineering 50, 012020 (2013).

8. A.E Ismail, A.K Ariffin, S. Abdullah, M.J Ghazali. International Journal of Automotive Technology, 12, 225-232 (2011).

9. L.S Chen, J.H Kuang. International Journal of Fracture 57, 51-58 (1992).

10. J. Albinmousa, N Merah, S.M.A Khan. Engineering Fracture Mechanics 78, 3300-3307 (2011).

11. A.E Ismail, A.L Mohd Tobi, N.H Mohd Nor. AIP Conference Proceedings 1660, 070027 (2015).

12. Y. Murakami, Stress Intensity Factors Handbook Volume 1, Pergamon Press (1987).

13. A.E Ismail, A.K Ariffin, S. Abdullah, M.J Ghazali. HKIE Transaction 18, 13-18 (2011). 